\title{
Optic Flow Stimuli Update Anterodorsal Thalamus Head Direction Neuronal Activity in Rats
}

\author{
Angelo Arleo, ${ }^{1,2}$ Cyril Déjean, ${ }^{1}$ Pierre Allegraud, ${ }^{2}$ Mehdi Khamassi, ${ }^{1}$ Michael B. Zugaro, ${ }^{1}$ and Sidney I. Wiener ${ }^{1,3}$ \\ ${ }^{1}$ Laboratory of Physiology of Perception and Action, CNRS-Collège de France, UMR 7152, 75231 Paris Cedex 05, France, ${ }^{2}$ Laboratory of Neurobiology of \\ Adaptive Processes, CNRS-University Pierre and Marie Curie, UMR 7102, 75005 Paris, France, and ${ }^{3}$ Memolife Laboratory of Excellence, Paris Science and \\ Letters University, 75005, Paris, France
}

Head direction (HD) neurons fire selectively according to head orientation in the yaw plane relative to environmental landmark cues. Head movements provoke optic field flow signals that enter the vestibular nuclei, indicating head velocity, and hence angular displacements. To test whether optic field flow alone affects the directional firing of HD neurons, rats walked about on a circular platform as a spot array was projected onto the surrounding floor-to-ceiling cylindrical black curtain. Directional responses in the anterodorsal thalamus of four rats remained stable as they moved about with the point field but in the absence of landmark cues. Then, the spherical projector was rotated about its yaw axis at $4.5^{\circ} \%$ for $\sim 90 \mathrm{~s}$. In 27 sessions the mean drift speed of the preferred directions $(\mathrm{PDs}) \mathrm{was} 1.48^{\circ} / \mathrm{s}\left(\mathrm{SD}=0.78^{\circ} / \mathrm{s}\right.$; range: 0.15 to $2.88^{\circ} / \mathrm{s}$ ). Thus, optic flow stimulation entrained PDs, albeit at drift speeds slower than the field rotation. This could be due to conflicts with vestibular, motor command, and efferent copy signals. After field rotation ended, $20 / 27 \mathrm{PDs}$ drifted back to within $45^{\circ}$ of the initial values over several minutes, generally following the shortest path to return to the initial value. Poststimulation drifts could change speed and/or direction, with mean speeds of $0.68 \pm 0.64 \%$ (range 0 to $1.36 \%$ ). Since the HD cell pathway (containing anterodorsal thalamus) is the only known projection of head direction information to entorhinal grid cells and hippocampal place cells, yaw plane optic flow signals likely influence representations in this spatial reference coordinate system for orientation and navigation.

\section{Introduction}

Head direction (HD) cells discharge as a function of the animal's head orientation in the azimuthal plane, regardless of the orientation of the head relative to the body, independently of the animal's ongoing behavior and of its spatial location. The HD cell system extends from the brainstem to the postsubiculum (Taube, 2007), which projects to the medial entorhinal cortex (MEC) (van Groen and Wyss, 1990), also containing HD cells (Sargolini et al., 2006). HD cells are thought to provide orientation information vital for grid and place cell activity in the entorhinalhippocampal system (Yoganarasimha and Knierim, 2005; Hargreaves et al., 2007). Grid cells of the dorsal MEC fire action potentials in a matrix of locations located at the vertices of a hexagonal grid and thus provide the brain with a metric for spatial representations (Fyhn et al., 2004). All existing computational models of grid cells require HD signals (Giocomo et al.,

Received June 18, 2013; revised Sept. 12, 2013; accepted Sept. 14, 2013.

Author contributions: A.A., M.B.Z., and S.I.W. designed research; A.A., C.D., P.A., M.K., and S.I.W. performed research; A.A. contributed unpublished reagents/analytic tools; A.A., P.A., and S.I.W. analyzed data; A.A. and S.I.W. wrote the paper.

This study was supported by French Ministère de la Recherche, Action Concertée Incitative "Neurosciences intégratives et computationelles," Centre National d'Etudes Spatiales, EC-contract FP6-IST-027140 BACS. Thanks go to Alain Berthoz, Christian Boucheny for help during some experimental sessions, Nicolas Lebas for help with the analysis, France Maloumian for preparing figures, Suzette Doutremer for histology, David Raballand for animal care, and Prof. Jeffrey $S$. Taube for comments on this manuscript.

Correspondence should be addressed to Sidney Wiener, Collège de France, UMR 7152, 11 place Marcelin Berthelot, 75231 Paris Cedex 05, France. E-mail: sidney.wiener@college-de-france.fr.

DOI:10.1523/JNEUROSCI.2698-13.2013

Copyright $\odot 2013$ the authors $\quad 0270-6474 / 13 / 3316790-06 \$ 15.00 / 0$
2011). In turn, grid cells constitute a main input to place cells of the dorsal hippocampus (Fyhn et al., 2004; Zhang et al., 2013).

How do environmental and self-movement information maintain these spatial representations? Grid, head direction, and hippocampal place cell responses are anchored by salient familiar landmark cues in the periphery (Cressant et al., 1997; Zugaro et al., 2001; Hafting et al., 2005). However, self-movement information is important for establishing and updating these representations (Knierim et al., 1998; Hafting et al., 2005; Taube, 2007). Such inputs would originate primarily in the vestibular end organs, motor command efferent collaterals, proprioception, and optic field flow. Indeed, head direction signals are first elaborated in brainstem structures including the vestibular nuclei. The vestibular nuclei receive optic flow signals (Waespe and Henn, 1977; Glasauer, 2005), which are then transmitted to the head direction cell pathway (Stackman and Taube, 1997; Stackman and Zugaro, 2005; Taube, 2007).

While several studies have compared the contributions of the respective types of self-movement cues to directional representations (Knierim et al., 1995, 1998; Zugaro et al., 2000; Stackman and Zugaro, 2005), little is known about the influences exerted by optic flow cues. Here, we test for this in anterodorsal (AD) thalamic head direction cells, which provide an appropriate experimental model for studying spatial representations.

\section{Materials and Methods}

Subjects. Four male Long-Evans (pigmented) rats (250-300 g; CERJ) were placed on a restricted food schedule to avoid excessive weight gain $(\sim 14 \mathrm{~g}$ of rat chow per day) with ad libitum access to water. The animals 
were maintained on a $12 \mathrm{~h} \mathrm{light} / 12 \mathrm{~h}$ dark cycle in an approved animal facility. All animal care and experimental protocols followed institutional and international standards, and legal regulations (Certificat ${ }^{\circ}$ 7186, Ministère de l'Agriculture et de la Pêche).

Electrode implantation. Electrode bundles consisting of eight formvarcoated nichrome wires (diameter $25 \mu \mathrm{m}$ ) were inserted in a 30 gauge stainless steel cannula, and mounted on one of two independently advanceable connector assemblies on a single headstage (Wiener, 1993). Before surgery, the animals were tranquillized with $0.1 \mathrm{ml}$ of xylazine and treated with pentobarbital $(40 \mathrm{mg} / \mathrm{kg}$ ). Local anesthesia (xylocaine) was applied at several points under the scalp. The electrodes were implanted above the anterodorsal thalamic nucleus (anteroposterior -1.4 to -2.0 $\mathrm{mm}$, and mediolateral \pm 1.1 to $\pm 1.4 \mathrm{~mm}$ relative to bregma, $4.2 \mathrm{~mm}$ ventral to brain surface) using conventional surgical techniques. The electrode descender assembly was permanently fixed to the skull with dental acrylic and tiny screws. A ground screw connector assembly was implanted in the cranial bone.

Data acquisition. Electrode signals passed through FETs, differentially amplified $(10,000 \times)$ and filtered $(300 \mathrm{~Hz}$ to $5 \mathrm{kHz}$, notch at $50 \mathrm{~Hz})$. The signal was then transmitted to a computer for automatic data collection. The acquisition software (DataWave Discovery) digitized and collected 32 data points (at $20 \mathrm{kHz}$ ) for each signal crossing a user-set threshold. Single unit activity was discriminated post hoc with this system using a maximum of eight waveform parameters.

Once a neuron was successfully isolated, the electrodes were not advanced to facilitate further recordings from the same neuron. The rationale for this was that in simultaneous recordings of head direction cells, all neurons respond coherently to cue manipulations (Taube and Burton, 1995). Thus, the responses would be the same in each isolated neuron as in its neighbor, which might have proven more difficult to discriminate.

Before recordings, a support with two small infrared light-emitting diodes (10 cm separation) was mounted above the headstage. The positions of the two lamps were detected by an overhead video camera (using the DataWave video-tracking system) and sampled at $60 \mathrm{~Hz}$. The heading direction of the animal was computed post hoc from the lamp positions. Inversions of their images due to tracking errors were corrected with our own interactive software. Counterclockwise rotations are considered positive.

Experimental apparatus and protocol. The animals were placed on a circular platform (diameter $75 \mathrm{~cm}$ ) at an elevation of $75 \mathrm{~cm}$ and surrounded and covered by a large cylindrical black curtain ( $3 \mathrm{~m}$ in diameter and height; Fig. 1). The curtain was hung tautly to avoid drapery folds. The floor was black and nonreflective. A planetarium-like projector presented a field of points in an irregular pattern of 4 and $12 \mathrm{~cm}$ circular spots evenly distributed at a density of $\sim 3$ spots $/ \mathrm{m}^{2}$ on the curtains of the otherwise dark room. The mean luminance of the spots was $0.075 \mathrm{~cd} / \mathrm{m}^{2}$. The platform was covered with wood shavings to reduce possible olfactory and proprioceptive contact cues.

First head direction cells were characterized under light conditions. The curtain was closed while one experimenter remained within. To rapidly and continually sample cell activity from all head orientations, when the rat stopped moving, the experimenter gently prodded it from behind with a Plexiglas ruler, attempting to encourage equal numbers of rotations in both directions, and quietly stirred the litter to obscure possible olfactory cues. The experimenter wore a dark lab coat and remained behind the rat to avoid providing orienting cues. The experimenter was often disoriented by the optic flow, even after many experiments.

The recording session started with the planetarium projector lit but stationary. Then, the point array was rotated at a constant velocity $\left[4.5^{\circ} \mathrm{s}\right.$; selected because of the high gain optokinetic neuronal responses it elicits (Reber et al., 1989)] for $\sim 90 \mathrm{~s}$ (thus rotating $405^{\circ}$ ), but in some cases ranging from 78 to $135 \mathrm{~s}$ (mean $=93.1 \mathrm{~s} ;$ SEM $=11.4 \mathrm{~s} ; t$ test comparisons of durations of point array rotation between rats: 2 vs $6, p=$ $0.11 ; 2$ vs $7, p=0.24 ; 2$ vs $8, p=0.30 ; 6$ vs $7, p=0.25 ; 6$ vs $8, p=0.24 ; 7$ vs $8, p=0.74)$. The rotation period was followed by recordings for several minutes with the point array stationary once again. In a few sessions, the point array was also turned off for a few minutes.

Data analysis. The directional firing parameters (PD, peak firing rate, firing range, baseline firing rate) were computed by using a Gaussian fit,

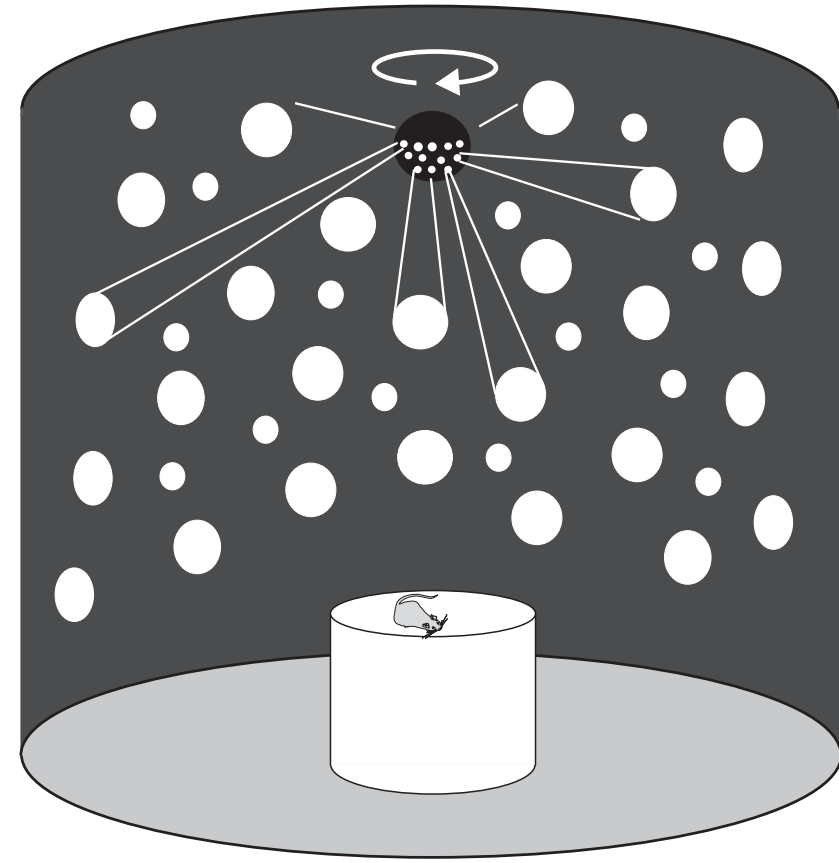

Figure 1. Schematic drawing of the experimental apparatus.

i.e., $f(\theta)=A+(B-A) \cdot e^{-\left(\theta-\theta^{\prime}\right)^{2} / 2 \sigma^{2}}$, where $f$ is the firing rate, $\theta$ the head direction, $\theta^{\prime}$ the $\mathrm{PD}, A$ the baseline firing rate, $B$ the peak firing rate, and $\sigma$ the SD of the tuning curve. A best-fit approximation to this curve was obtained via Matlab (MathWorks) software (least-square distance obtained with a Nelder-Mead type simplex search method). The directional firing range was determined as the width of the curve at the baseline level, computed using the two tangent lines at the inflection points of the Gaussian curve. Neurons with a peak-to-baseline firing rate ratio exceeding 2.5 were retained for subsequent analyses.

The time course of the PD was assessed through maximum likelihood estimation. The discharge probability of a neuron was modeled as the above Gaussian-like spike frequency distribution $f(\theta)$. The number of spikes $c(t)$ recorded during a time step $d t$ was assumed to follow a Poisson law $c(t)=$ $P\left(f\left(\theta^{\prime}, \theta, A, B, \sigma\right) d t\right.$, with $d t=0.1 \mathrm{~s}$. The PD over time $\theta^{\prime}(t)$ was approximated as a piecewise linear function $\hat{\theta}^{\prime}(t)=\left\{\theta^{\prime}\left(t_{0}\right), \theta^{\prime}\left(t_{1}\right), \ldots, \theta^{\prime}(T)\right\}$, with $T$ denoting the duration of a trial and $t_{0}<t_{1}<\ldots<T$, such that: $\theta^{\prime}(t)=\frac{t-t_{i+1}}{t_{i}-t_{i+1}} \theta^{\prime}\left(t_{i}\right)+\frac{t-t_{i}}{t_{i+1}-t_{i}} \theta^{\prime}\left(t_{i+1}\right), \forall t \in\left[t_{i}, t_{i+1}\right]$. Then, the parameters of both the tuning curve $f(\theta)$ and the piecewise linear function $\hat{\theta}^{\prime}(t)$ were tuned by optimizing the function $L(\Theta, c)=\sum_{t}(f(t, \Theta) d t-c(t) \log (f(t, \Theta)))$, with $\Theta=\left\{A, B, \sigma, t_{1}, \ldots, t_{T-1}, \theta_{0}^{\prime}, \theta_{1}^{\prime}, \ldots, \theta_{T}^{\prime}\right\}$. Given the initial conditions $\Theta_{0}$, a gradient descent method was used to best fit the parameter values recurrently, that is, $\Theta_{n+1}=\Theta_{n}-\alpha_{n} \frac{\partial L\left(\Theta_{n}, c\right)}{\partial \Theta}$, where $\alpha_{n}$ is a gain matrix. The number of inflection points $\left\{t_{1}, \ldots, t_{T-1}\right\}$ reflected the rate of change of the $\mathrm{PD}$ over time. This was found iteratively by running the optimization algorithm for $2,3,4, \ldots, 8$ inflection points to seek the best compromise between residual error minimization and overfitting. The value of 3 was found to be most parsimonious.

Histology. At the end of the experiments, a small cathodal DC current $(20 \mu \mathrm{A}, 10 \mathrm{~s})$ was passed through one of the recording electrodes, making a small electrolytic lesion to mark the tip location. The rats were subsequently deeply anesthetized with pentobarbital. Intracardial perfusion with saline was followed by $10 \%$ formalin-saline. Histological sections were stained with cresyl violet. Recording sites were reconstructed by detecting the small lesion and the track of the 30 gauge cannula, and taking into account the distance that the microelectrode driver had been advanced from the point of stereotaxic placement of the electrodes. Recording sites were calculated by interpolation along the electrode track between the lesion and implantation sites. 

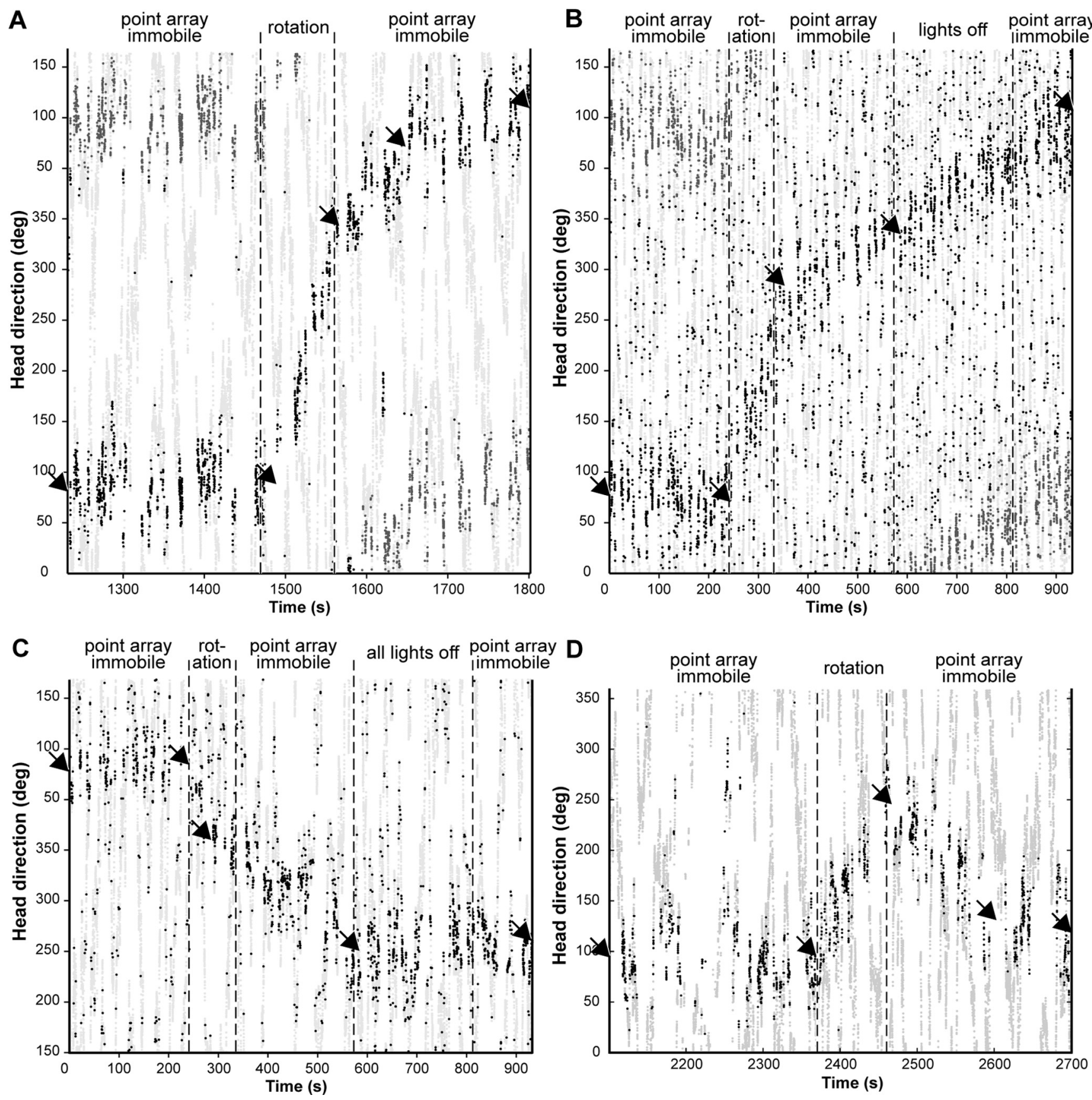

Figure 2. AD thalamic head direction neuron activity in experiments from three different rats. Light gray points indicate the head orientation of the rat. Black points indicate timing of action potentials (100 ms binning). Gaps indicate moments when the rat was not oriented in the PD, or in rare cases, tracking system detection failures. The y axis is repeated to demonstrate the continuity of PD drift (medium gray points are redundant). Arrows show inflection points detected by the algorithm. In all cases the PD remained stable during the initial period with the point array immobile, then drifted coherently in the same direction as the rotational optic flow. $A$, After the field flow stimulation stopped, the PD continued to drift and at the end of recording returned close to the original value (Rat 2). $\boldsymbol{B}$, Responses similar to $\boldsymbol{A}$ albeit in a recording with a lower drift rate (Rat 8). C, A session with counterclockwise stimulation. Here, the algorithm detected an inflection in the drift rate during stimulation and poststimulation drift ceased once the point display was extinguished, without returning to the initial PD (Rat 7). D, Poststimulation drift in the opposite direction of initial drift (from the trial following that in Fig. 2A; Rat 2).

\section{Results}

In four rats, a total of 27 recording sessions had well discriminated neurons ( $n=8,6,8$ and 5 , respectively), 15 with clockwise and 12 with counterclockwise rotations of the light spot array.

In all sessions, during the first period when the spot array was immobile, all head direction responses remained stable, that is, initial and final values of the decoded PD did not vary (mean absolute shift: $11.8 \pm 12.5^{\circ} \mathrm{SD}$; $V$ test: $p=6.396 \cdot 10^{-12}$; Fig. 2 ). Directional firing ranges averaged $102^{\circ}\left( \pm 17^{\circ} \mathrm{SD}\right.$; range: $78-$ $151^{\circ}$; only one sample was taken per day to avoid multiple counts of the same neuron; $n=13$ ). For comparison, Taube (1995) observed in a sample of $37 \mathrm{AD}$ thalamus neurons an average range of $96.24^{\circ}\left( \pm 3.25^{\circ} \mathrm{SEM}\right.$; range $\left.60.94-142.97^{\circ}\right)$ under normal lighting conditions. In only two cases was there a second smaller peak in the tuning curve: one seemed to be due to drift while the other appeared to be a poorly discriminated simultaneous recording of a second neuron. Thus, the point array as well as vestibular, motor command efferent and proprioceptive cues 
generally provided sufficient information to maintain these directional responses stable despite the absence of prominent landmark cues. The failure of static visual cues (provided by the spot array) to anchor the directional responses was verified by emulating Taube's (1995) cue card rotation experiment. At the beginning of the first session of the day, after a stable directional response had been established with the point array immobile, it was turned off and rotated by $90^{\circ}$. The point array was then turned back on and the directional response reassessed. The reorientation effect on PDs was negligible (range: $2.1-16.8^{\circ}$; mean absolute shift: $7.1 \pm 4.7^{\circ} \mathrm{SD} ; n=16$; $V$ test: $p=1.03 \cdot 10^{-8}$ ).

However, continual rotation of the point array consistently induced a drift in directional responses in the same direction (Fig. 2 ). The mean drift speed of the directional responses was 1.48 $( \pm 0.78)^{\circ} \%$ s. This is one-third the stimulus rotation rate, indicating that the optic flow cues incompletely controlled the directional updating. The values of the average speeds (in $\%$ ) are listed in the chronological order of the sessions that they were recorded, with values from the same session grouped in braces, and from the same day (but different sessions) in brackets: Rat 2: 1.43, $[\{2.88,2.08,1.69\},\{2.42,2.82,1.74,2.43\}]$; Rat $6:\{0.43,0.15$, $0.70\}, 1.49,\{0.59,0.99\}$; Rat $7:\{1.58,1.67,1.36\}, 0.76,[\{0.80$, $2.38\}, 0.85], 0.72$; Rat 8: [\{1.17, 1.92\}, $\{1.96,2.42\}], 0.56$. There are no strikingly apparent tendencies for changes in responses with increased experience. Note that drift speeds varied between subsequent sessions recorded from the same animal (Fig. 2, compare $A, D)$. According to the inflection point analysis, in most cases the PD began to drift at or shortly after the onset of the optic flow stimulus ( 18 sessions with no delay, the others were $-17,5$, $7,9,10,17,27$, and $27 \mathrm{~s}$ ), and in three sessions the drift rate increased during the optic flow rotational stimulation.

Several different behavioral parameters were tested for possible correlations with the varying magnitudes of the average drift speeds. For example, had the animals rotated preferentially in one direction during the stimulation, this could have increased or decreased the net optic flow that was experienced. But analyses correlating drift speed with either the net rotation angle or the differences in numbers of clockwise and counterclockwise rotations over successive $0.2 \mathrm{~s}$ windows in the session yielded no significant correlations for the entire group or for individual animals (two-tailed Pearson product-moment correlations; $p>$ $0.05)$. Analyses of differences in clockwise and counterclockwise mean velocities or accelerations of the animal or of the net optic flow also yielded no significant correlations in the Pearson tests. Inspection of successive positions of the headlamps during optic flow stimulation revealed no obvious differences in rearing incidences or visits to the edge of the platform in low versus high drift speed sessions (these events could have altered the perceived optic flow). Drift speeds were greater (Student's $t$ test: $p=0.0033$ ) for counterclockwise stimuli $\left(1.94 \pm 0.64^{\circ} / \mathrm{s}\right)$ than for clockwise stimuli $\left(1.11 \pm 0.68^{\circ} / \mathrm{s}\right)$. But this could be confounded by differences in mean drift speeds among the four rats: $2.19 \pm 0.54$, $0.72 \pm 0.46,1.26 \pm 0.60$, and $1.60 \pm 0.74 \%$ s (see Fig. 3 for distributions of drift angles). While Rat 8 had the highest SEM, the variances were not significantly different among the rats (pairwise comparison $F$-tests, all $p>0.05$ ). Since unequal numbers of clockwise and counterclockwise sessions were retained for the respective animals, the greater average speed for counterclockwise rotations could derive from interindividual differences.

Strikingly, after the point array rotation stopped, the PDs generally drifted back toward the initial values. In 20 of the 27 sessions, the final PD after this drift was within $45^{\circ}$ of the initial value (Rat 2: 7 of 8 ; Rat $6: 6$ of 6 ; Rat 7:3 of 8 , and Rat $8: 4$ of 5 ), deviating

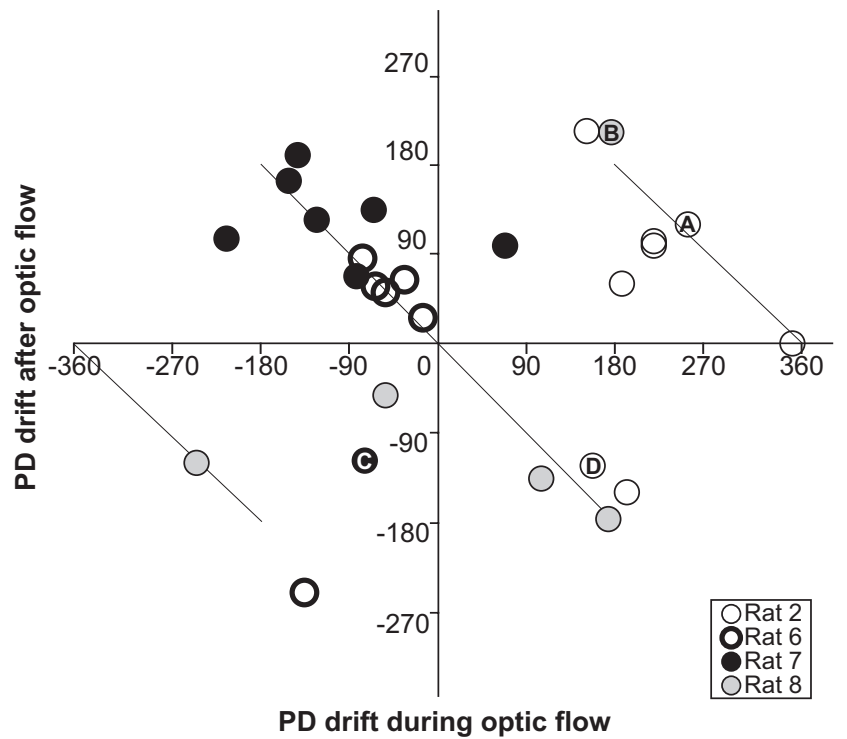

Figure 3. The direction and magnitude of the poststimulation drift as a function of the drift amplitude during stimulation. Note that for Rats 2, 6, and 7 the respective magnitudes of PD drifts during optic flow appear to be more clustered than in Rat 8 , consistent with this rat showing the greatest drift speed SEM $\left( \pm 0.74^{\circ} / \mathrm{s}\right)$. Diagonal lines mark equal amplitudes. When PD drifts during stimulation were on the order of or $\angle 180^{\circ}$, poststimulation drifts tended to return in the opposite direction, while in the other cases drift continued in the same direction as during stimulation. Letters indicate the sessions displayed in Figure 2.

significantly from a random distribution (Rayleigh test: $p=$ $\left.1.046 \cdot 10^{-10}\right)$. These drifts lasted from $100 \mathrm{~s}$ to over $600 \mathrm{~s}$ (Fig. 2), in some sessions apparently continuing at the end. Speeds within these periods averaged $0.59( \pm 0.54)^{\circ} \% \mathrm{~s}$ and ranged from zero to $1.59^{\circ} / \mathrm{s}$. In 14 sessions the drift plot showed an inflection in the post-optic flow period due to a change in drift direction $(n=7)$ and/or in speed (Fig. 2A). No consistent differences were found between poststimulation periods whether the (immobile) point array was on or off (Fig. $2 B$ ).

The direction of drift during the return to the initial PD varied, and tended to follow the shortest path through the intermediate angles. In Figure 3, for optic flow stimulation period drifts of magnitudes $<180^{\circ}$, the points along the diagonal line passing through the origin correspond to post-stimulation drifts in the opposite direction (as in Fig. 2D). For greater drifts during the optic flow period, the points along the other two diagonal lines correspond to further drift continuing in the same direction (Fig. $2 A, B)$.

\section{Discussion}

The principal findings here are as follows: (1) rat HD neuron PDs remain stable with only a point array for illumination, in the absence of prominent landmark cues; (2) optic field flow provokes PD drift; (3) these drift speeds vary among sessions; (4) after point array rotation stops, the PDs continue to drift, albeit more slowly, often returning close to the original orientation.

These drifts in PD recall the perceptual illusion of self-movement (vection) induced by optic field flow (Israël and Warren, 2005), wherein the optic field is erroneously taken as immobile and the system reacts as if the animal had moved. This occurs despite conflicts with internal signals (vestibular, motor command, and efferent copy) indicating no such self-rotation. Such conflicts could explain why the cells' PD drift speeds were lower than the optic field flow rate. Variations among the drift speeds could not be conclusively linked with any particular characteristics of the rats' movement dy- 
namics. Perhaps such a relationship may be found in future experiments specifically designed to test for this. The individual rats had different average drift rates and Rat 8 appeared to have less clustering of the values of drift speeds than the other rats. These variations could be related to interindividual differences in the dominance of these respective cues for estimating movement in cue conflict situations (Lambrey and Berthoz, 2007; Fetsch et al., 2009). In a study of hippocampal place responses in a virtual reality experiment (Chen et al., 2013), individual rats showed differences in the respective influences of visual versus movement cues.

Blair and Sharp (1996) tested the effect of visual motion on $\mathrm{AD}$ head direction cells in a large cylinder marked with four alternating series of $45^{\circ}$ wide black and white stripes. After rapid rotation of the cylinder wall by $90^{\circ}$, six of eight neurons shifted by $<25^{\circ}$, one by $\sim 45^{\circ}$, and the other by $90^{\circ}$. They concluded that visual motion information has only a weak (or no) influence on head direction cells. The differences with the present findings may be due to their stimulus type and duration being suboptimal for optic flow stimulation and also could be related to the motor state of the animal. For optokinetic or optic flow experiments, optimal stimuli are typically random dot displays or stripes at higher spatial frequencies, and stimulation continues over longer durations (Israël and Warren, 2005). Zugaro et al. (2000) also rapidly rotated the cylindrical wall of the arena by 45 or $90^{\circ}$ in the presence of the rats but found that PDs shifted by $\sim 10 \%$ less than the wall. Stackman et al. (2003) demonstrated elevated variability in PDs when rats moved between a familiar and an unfamiliar environment when optic flow cues were unavailable. Several other studies have examined the effects of moving the visual field on hippocampal spatial responses (Sharp et al., 1995; Terrazas et al., 2005; Harvey et al., 2009; Lu and Bilkey, 2010; Hüfner et al., 2011), but none examined yaw plane rotational optic flow stimuli independently. In most cases, the real or virtual visual stimuli might have been sensed as objects or landmarks, which might be processed by different brain pathways than the current stimuli that more specifically and exclusively induce optic field flow.

PD drift has been reported previously (for review, see Knierim, 2005). The present observation of the ultimate return of PDs to the initial orientation in 20/27 sessions suggests the influence of some unidentified landmark cue. The tendency of the PDs to migrate along the shortest angular path to return to the initial orientations is consistent with the properties of an attractor network (Degris et al., 2004; Boucheny et al., 2005). Several other studies have also reported drift in head direction cells, typically in cue conflict or diminished cue situations (Knierim et al., 1995; Goodridge and Taube, 1995). The inflection point analysis revealed some delays in the onset of drift after the start of optic flow stimulation-comparable delays were also observed by Knierim et al. (1998).

The present findings have bearing on the mechanisms by which self-movement cues contribute to updating coherent spatial representations during the animal's movements. Indeed, optic flow provokes changes in the head orientation representations of $\mathrm{AD}$ neurons that in turn would influence the activity of place and grid cells. Brain representations of orientation and position in space are elaborated on the basis of distal landmark and selfmotion cues. The importance of the latter in updating representations of position and orientation in space, or "path integration," is particularly highlighted in grid cell activity. The cells' responses at successive grid nodes would require updating of distances and angles of movements. The head direction cell pathway (including the $\mathrm{AD}$ ) is the only known projection carrying head direction signals to the layer of the MEC that has head direction cells and grid cells (Taube, 2007). The present work then supports a contribution of optic field flow to the grid navigational reference system via the head direction system.

\section{References}

Blair HT, Sharp PE (1996) Visual and vestibular influences on headdirection cells in the anterior thalamus of the rat. Behav Neurosci 110: 643-660. CrossRef Medline

Boucheny C, Brunel N, Arleo A (2005) A continuous attractor network model without recurrent excitation: maintenance and integration in the head direction cell system. J Comput Neurosci 18:205-227. CrossRef Medline

Chen G, King JA, Burgess N, O’Keefe J (2013) How vision and movement combine in the hippocampal place code. Proc Natl Acad Sci U S A 110: 378-383. CrossRef Medline

Cressant A, Muller RU, Poucet B (1997) Failure of centrally placed objects to control the firing fields of hippocampal place cells. J Neurosci 17:25312542. Medline

Degris T, Sigaud O, Wiener SI, Arleo A (2004) Rapid response of head direction cells to reorienting visual cues: a computational model. Neurocomputing 58-60C:675-682.

Fetsch CR, Turner AH, DeAngelis GC, Angelaki DE (2009) Dynamic reweighting of visual and vestibular cues during self-motion perception. J Neurosci 29:15601-15612. CrossRef Medline

Fyhn M, Molden S, Witter MP, Moser EI, Moser MB (2004) Spatial representation in the entorhinal cortex. Science 305:1258-1264. CrossRef Medline

Giocomo LM, Moser MB, Moser EI (2011) Computational models of grid cells. Neuron 71:589-603. CrossRef Medline

Glasauer S (2005) Vestibular and motor processing for head direction signals. In: Head direction cells and the neural mechanisms of spatial orientation (Wiener SI, Taube JS, eds), pp 113-135. Cambridge, MA: MIT.

Goodridge JP, Taube JS (1995) Preferential use of the landmark navigational system by head direction cells in rats. Behav Neurosci 109:49-61. CrossRef Medline

Hafting T, Fyhn M, Molden S, Moser MB, Moser EI (2005) Microstructure of a spatial map in the entorhinal cortex. Nature 436:801-806. CrossRef Medline

Hargreaves EL, Yoganarasimha D, Knierim JJ (2007) Cohesiveness of spatial and directional representations recorded from neural ensembles in the anterior thalamus, parasubiculum, medial entorhinal cortex, and hippocampus. Hippocampus 17:826-841. CrossRef Medline

Harvey CD, Collman F, Dombeck DA, Tank DW (2009) Intracellular dynamics of hippocampal place cells during virtual navigation. Nature 461: 941-946. CrossRef Medline

Hüfner K, Strupp M, Smith P, Brandt T, Jahn K (2011) Spatial separation of visual and vestibular processing in the human hippocampal formation. Ann NY Acad Sci 1233:177-186. CrossRef Medline

Israël I, Warren WH (2005) Vestibular, proprioceptive and visual influences on the perception of orientation and self-motion in humans. In: Head direction cells and the neural mechanisms of spatial orientation (Wiener SI, Taube JS, eds), pp 347-381. Cambridge, MA: MIT.

Knierim JJ (2005) Coupling between head direction cells and place cells: influences of landmarks, self-motion, and intrinsic circuitry. In: Head direction cells and the neural mechanisms of spatial orientation (Wiener SI, Taube JS, eds), pp 163-185. Cambridge, MA: MIT.

Knierim JJ, Kudrimoti HS, McNaughton BL (1995) Place cells, head direction cells, and the learning of landmark stability. J Neurosci 15:16481659. Medline

Knierim JJ, Kudrimoti HS, McNaughton BL (1998) Interactions between idiothetic cues and external landmarks in the control of place cells and head direction cells. J Neurophysiol 80:425-446. Medline

Lambrey S, Berthoz A (2007) Gender differences in the use of external landmarks versus spatial representations updated by self-motion. J Integr Neurosci 6:379-401. CrossRef Medline

Lu X, Bilkey DK (2010) The velocity-related firing property of hippocampal place cells is dependent on self-movement. Hippocampus 20:573-583. Medline

Reber A, Lannou J, Hess BJ (1989) Development of optokinetic neuronal responses in the pretectum and horizontal optokinetic nystagmus in unilaterally enucleated rats. Arch Ital Biol 127:225-242. Medline

Sargolini F, Fyhn M, Hafting T, McNaughton BL, Witter MP, Moser MB, 
Moser EI (2006) Conjunctive representation of position, direction, and velocity in entorhinal cortex. Science 312:758-762. CrossRef Medline

Sharp PE, Blair HT, Etkin D, Tzanetos DB (1995) Influences of vestibular and visual motion information on the spatial firing patterns of hippocampal place cells. J Neurosci 15:173-189. Medline

Stackman RW, Taube JS (1997) Firing properties of head direction cells in the rat anterior thalamic nucleus: dependence on vestibular input. J Neurosci 17:4349-4358. Medline

Stackman RW, Zugaro MB (2005) Self-motion cues and resolving intermodality conflicts: Head direction cells, place cells and behavior. In: Head direction cells and the neural mechanisms of spatial orientation (Wiener SI, Taube JS, eds), pp 137-162. Cambridge, MA: MIT.

Stackman RW, Golob EJ, Bassett JP, Taube JS (2003) Passive transport disrupts directional path integration by rat head direction cells. J Neurophysiol 90(5):2862-2874. CrossRef

Taube JS (1995) Head direction cells recorded in the anterior thalamic nuclei of freely moving rats. J Neurosci 15:70-86. Medline

Taube JS (2007) The head direction signal: origins and sensory-motor integration. Annu Rev Neurosci 30:181-207. CrossRef Medline

Taube JS, Burton HL (1995) Head direction cell activity monitored in a novel environment and during a cue conflict situation. J Neurophysiol 74:1953-1971. Medline

Terrazas A, Krause M, Lipa P, Gothard KM, Barnes CA, McNaughton BL
(2005) Self-motion and the hippocampal spatial metric. J Neurosci 25: 8085-8096. CrossRef Medline

van Groen T, Wyss JM (1990) The postsubicular cortex in the rat: characterization of the fourth region of the subicular cortex and its connections. Brain Res 529:165-177. CrossRef Medline

Waespe W, Henn V (1977) Vestibular nuclei activity during optokinetic after-nystagmus (OKAN) in the alert monkey. Exp Brain Res 30:323-330. Medline

Wiener SI (1993) Spatial and behavioral correlates of striatal neurons in rats performing a self-initiated navigation task. J Neurosci 13:3802-3817. Medline

Yoganarasimha D, Knierim JJ (2005) Coupling between place cells and head direction cells during relative translations and rotations of distal landmarks. Exp Brain Res 160:344-359. CrossRef Medline

Zhang SJ, Ye J, Miao C, Tsao A, Cerniauskas I, Ledergerber D, Moser MB, Moser EI (2013) Optogenetic dissection of entorhinal-hippocampal functional connectivity. Science 340:1232627. CrossRef Medline

Zugaro MB, Tabuchi E, Wiener SI (2000) Influence of conflicting visual, inertial and substratal cues on head direction cell activity. Exp Brain Res 133:198-208. CrossRef Medline

Zugaro MB, Berthoz A, Wiener SI (2001) Background, but not foreground, spatial cues are taken as references for head direction responses by rat anterodorsal thalamus neurons. J Neurosci 21:RC154(1-5). Medline 